\title{
The Place of
}

\section{Practice-Centered Inquiry \\ in a Faculty Development}

Program

Nancy Van Note Chism and Donald P. Sanders

The Ohio State University.

Those who study and practice college teaching have long believed that effective college teachers acquire their professional skill largely on the job, through experience and through a practical kind of inquiry that enables them to reflect on their teaching and develop ongoing plans for action. Recent scholarship on the nature of inquiry in professional practice (Argyris, 1982; Argyris, et. al., 1985; Schon, 1983), and specifically in teaching (Carr \& Kemmis, 1983; Tripp, 1984; Sanders \& McCutcheon, 1984), has supported this belief, offering important insights that can be used productively in conceptualizing and developing programs for faculty development. A common argument in these works is that effective professionals improve their practice through an inquiry process (which will be called practicecentered inquiry in this paper) that enables them to bring reflection to bear in the action context in which they function.

Applied to the case of faculty members, the idea is that through continually inquiring into the many puzzles, surprises, problems, and interesting situations that arise in teaching, effective faculty members build up a store of knowledge that is used to appreciate, interpret, and guide actions in new situations. This knowledge also allows them to recognize and work toward the resolution of problems in the larger environment that impact upon their work.

The frequent claims by faculty members that they learn 
"through experience" or by "trial and error" offer ample evidence that faculty members recognize that a large part of their knowledge about teaching has developed through these ongoing cycles of experimentation and reflection. Their preferences for personal forms of practice-centered inquiry seem quite appropriate, since practice-centered inquiry seems to be ideally suited to their professional learning and effective performance for several reasons:

1. In practice-centered inquiry, learning is firmly grounded in a practical, concrete problem or issue that arises in teaching. This immediacy makes the problem or issue compelling for the inquiring teacher and helps to enhance the quality of the learning that takes place, since knowing what to do in subsequent situations is a significant motive for practitioners.

2. Since practice-centered inquiry arises in the teaching context, it can address the particulars of that context within the current perspective of the inquiring teacher. It is flexible enough to fit a unique teaching situation, whether it calls for a relatively formal systematic inquiry, or for intuition, casual observation, or momentary reflection. It does not assume either fixed conditions or predictability in the teaching situation, but rather a dynamic flow of events that will continually demand new responses and instances of inquiry. Thus, it can be responsive to each unique teaching situation with all its uncertainty, instability, and complexity.

3. Unlike traditional forms of inquiry, practice-centered inquiry accommodates and even demands consideration of questions of value that are so central to teaching. Inquiring faculty members are continually forced by the nature of educational situations to recognize and deal with valueladen issues. Practice-centered inquiry often raises unquestioned assumptions to a conscious level, encouraging a higher form of learning that Argyris (1982) has termed "double loop learning," learning that not only examines the immediate set of circumstances but also the framework of assumptions and concepts within which one is viewing the circumstances.

4. Practice-centered inquiry has enabling effects. When faculty members increase their understanding of what is going on 
in their teaching and generate practices that are effective for them, they often feel a sense of empowerment as well as achievement. Empowerment, in turn, engenders a sense of commitment to teaching and may result in increased awareness of constraining forces in university or departmental policies (such as time schedules or grading policies) that may need improvement. Inquiring faculty members thus may become more proactive in shaping the environment at their college or university for the improvement of teaching.

Donald Schon (1983) summarizes the importance of reflection for professionals:

When someone reflects-in-action, he becomes a researcher in the practice context. He is not dependent on the categories of established theory and technique, but constructs a new theory of the unique case. His inquiry is not limited to a deliberation about means which depends on a prior agreement about ends. He does not keep means and ends separate, but defines them interactively as he frames a problematic situation. He does not separate thinking from doing, ratiocinating his way to a decision which he must later convert to action. Because his experimenting is a kind of action, implementation is built into his inquiry.

(p.68)

\section{FACULTY USE OF PRACTICE-CENTERED INQUIRY}

Most faculty members inquire into their practice, either sporadically or fairly continuously. When faced with an unexpected student response, a disappointing set of exams, or a surprisingly successful lab, they ask what set of factors might have produced the situation, and they use this knowledge in deciding future courses of action, either immediate or longterm. In this manner, faculty members build up a stock of practical knowledge, rules of thumb, expectations, and hunches that guide their practice.

Faculty use of practice-centered inquiry might be described in terms of a continuum of activities. At the lower end of the continuum are the fleeting thoughts, observations, realizations, and questions that arise during the process of teaching, such as the observation that a particular discussion topic elicited a great deal of response (and the consequent mental note to use that or similar questions again when the same result is desired). 
At the middle range of the practice-centered inquiry continuum are informal types of inquiry that are somewhat sustained. For example, the professor might reflect at some length on why that particular discussion question worked or might ask some students or colleagues to suggest some reasons. The faculty member might even decide to keep some notes on specific questions used and observed responses, which would be reviewed periodically for patterns to derive some general personal guidelines for developing discussion questions.

At the high end of the practice-centered inquiry continuum are formal research studies in which the faculty member might actually develop a research design and approach the situation in a highly systematic fashion. In the example of the discussion question, the professor might arrange to experiment with a variety of questions, using the fieldnotes of a nonparticipant observer, interview data, results from a questionnaire, or test results to judge the impact of various kinds of questions under various conditions. The faculty member might analyze the results and arrive at a typology of questions or questioning principles that can inform future duscussion planning.

Because they are limited in the amount of time and energy that they can devote to teaching and because they thus tend to develop theories and routines that generally serve "well enough" in dealing with the complexities of teaching, faculty members usually use practice-centered inquiry very informally. Many reserve sustained reflection on teaching for moments of crisis or approach the examination of their practice rather unsystematically, relying on habit or tradition under everyday conditions. Furthermore, professors who have difficulty in their teachirig often seem to be especially unreflective and not interested in inquiring into their teaching practices. Often, for the promise that practice-centered inquiry holds for faculty development to be realized, then, external assistance and encouragement are needed.

\section{IMPLICATIONS FOR}

\section{FACULTY DEVELOPMENT PROGRAMS}

Helping faculty to develop a capacity and habit for engaging in ongoing systematic reflection on their practice can be seen as central to the work of faculty development. One reason for 
this, as Schon (1983) points out, is that such habits can not only enable improved instruction but also professional renewal:

When a practitioner becomes a researcher into his own practice, he engages in a continuing process of self-education. When practice is a repetitive administration of techniques to the same kinds of problems, the practitioner may look to leisure as a source of relief, or to early retirement, but when he functions as a researcherin-practice, the practice itself is a source of renewal.

(p. 29)

Because such an approach brings the developer close to the natural process through which faculty members develop new understandings of their teaching and make changes in their practice, the developer can root development activities in a context, providing an immediate frame of reference for the normal consulting activities, materials development and dissemination, and instruction on particular teaching skills that frequently account for a large part of faculty development work.

There are several ways in which faculty developers can facilitate practice-centered inquiry. Recognizing that casual reflection and inquiry will be the only course of action feasible for many faculty members, the developer can assist by providing occasions for reflection, such as conversation sessions devoted to dialogue about specific issues of practice identified by participants, periodic self-assessment through writing (Clader, 1980 ) or retreats, course planning meetings, and the like. Faculty members might be invited to record their "teaching puzzle of the week" or high and low points in their teaching and share these with colleagues at periodic meetings arranged by the faculty development office. Discussing videotapes of a class or results of student tests can often provide the occasion for recognizing and exploring teaching puzzles that have previously been ignored.

In the case of faculty who are ready or able to extend their inquiry activities, faculty developers can help by presenting occasions for deeper reflection and inquiry. As faculty members draw on their concepts, schemata, and theories of teaching to conceive or model an issue or problem, discussions with peers or a faculty developer can help to bring unexamined assumptions or unconscious beliefs about teaching to the point of articulation. For example, in one such discussion, a faculty member who wanted to explore how to protect exam security was stimulated by his colleagues to think through whether it was 
important for exams to be surprises. He was prompted to rethink his problem at a more fundamental level and to approach his inquiry and subsequent practice in a different light. In addition to dialogue, faculty developers can promote writing, such as maintaining personal teaching journals (Oberg, 1985) as a vehicle for enhancing reflection and revealing assumptions about teaching.

Faculty developers might also encourage faculty members who can engage in more sustained inquiry to collect detailed information on the long-term effects of specific practices, emphasizing the importance of obtaining informative feedback on teaching through a variety of vehicles ranging from periodic checks with students, observation by colleagues, and careful monitoring of student work. (Wilson, et. al., 1984, provide many methods for accornplishing these activities.) The faculty developer might use a consulting session to suggest specific ways in which a faculty member might collect information that will help define problems and strengths in practice and might even offer assistance in collecting and analyzing the information that is obtained.

Periodically, for certain questions or under certain circumstances, when faculty members elect to use practice-centered inquiry in a highly sustained and systematic fashion, they can be offered assistance in the form of challenge and support at several points in the inquiry process. These phases are described below:

Framing the Inquiry Question. As faculty members shape their issue or problem into a question that can be answered by reference to things about which they may feasibly collect information, consultation with a colleague or faculty developer who has an interest and expertise in the design of research in social settings can help to frame the question in a way that will permit effective subsequent inquiry. In such a consultation, for example, a professor of art history who proposed exploring some general questions about the effects of her course on students' aesthetic understanding was encouraged to define and delimit the research question more clearly in light of what evidence could be collected. She chose to focus on the student response to different modes of presentation, a narrower but more approachable question. 
Designing the Study. Similarly, faculty members can be assisted by colleagues or faculty developers experienced in research in natural settings in the selection and development of an appropriate plan for collecting, analyzing, assessing and interpreting information effectively and efficiently. Often, strategies for conducting classroom research are unfamiliar to faculty members who have specialized in other research approaches. Faculty members can be apprised of the possibilities and problems associated with survey research, naturalistic inquiry, and other approaches, and helped to think through what resources would be required for the research activities.

Collecting Information. In more elaborate instances of inquiry, when the study design calls for non-participant observation, construction of a survey instrument, test item analysis or the like, faculty members will often require technical assistance and resources to carry out their design. The developer can suggest possible sources for this assistance, such as the staff of the faculty development center, departmental support in the form of student help or financial resources, or a small grant from a teaching improvement fund.

Analyzing the Information. Examining the information and drawing inferences and meaning from it are other activities that can also be enhanced through dialogue with colleagues or a faculty developer. In one such dialogue, for example, a faculty member who chose to discuss his test item analysis with colleagues and a developer drew on their past experiences and hunches to ask deeper questions of his data and gain insights that helped him to interpret his results. Students who are willing to analyze the information from their perspective may be another source of help available to faculty members.

Interpreting the Information. Faculty members can be assisted in making sense of the findings in terms of their original inquiry question and the issue or problem from which it arose by once again having access to opportunities for dialogue with colleagues or a faculty development consultant. Such dialogue can be extremely helpful in enabling the faculty member to view the findings in light of implications for practice. 


\section{QUESTIONS TO CONSIDER}

While supporting practice-centered inquiry is an attractive approach to the improvement of teaching, the idea raises several questions for faculty developers to consider as they experiment with ways to promote and support faculty reflection and inquiry:

1. Since systematic practice-centered inquiry often requires such scarce resources as extensive time and technical expertise, how can a single faculty development office at a large university work toward providing enabling conditions for all faculty?

2. Is facilitating systematic practice-centered inquiry an equally appropriate approach to take with new teaching assistants, new faculty members, and experienced faculty, or is it more effective during some career stages than others?

3. Is facilitating practice-centered inquiry a more appropriate approach to use with some faculty members than others, given the range of attitudes, personal characteristics, knowledge, and skills that faculty members bring to their teaching?

4. Does isolating and cultivating a specific instance of practicecentered inquiry have any long-term impact on improving subsequent use of inquiry by the faculty member?

5. Is facilitating practice-centered inquiry an effective approach for a wide range of instructional problems or is it best used with a particular type of problem or developmental issue?

6. What techniques can help facilitators in a faculty development office assist faculty members to recognize interesting or problematic facets of their teaching and tacit assumptions that they make about teaching and learning that influence their practice?

7. If the sense of empowerment that arises in faculty discussion leads to action, will the faculty development office find itself engaged in complex organizational issues that are beyond its control?

8. How can the facilitation of practice-centered inquiry best be integrated with other faculty development activities undertaken by a faculty development office? 
These issues can be addressed most fittingly through continuing inquiry by faculty developers into their own practices. As new interventions and experiences are examined and assessed, perhaps directions for future action in furthering faculty development through practice-centered inquiry will be suggested, stimulating new cycles of action and reflection that will continue to enrich the understanding and practice of faculty development.

\section{REFERENCES}

Argyris, C. (1982). Reasoning, learning, and action. San Francisco: JosseyBass.

Argyris, C., Putnam, R., \& Smith, D. (1985). Action science. San Francisco: Jossey-Bass.

Carr, W. \& Kemmis, S. (1983). Becoming critical: Knowing through action research. Victoria, Australia: Deakin University Press.

Clader, L. (1980). Self-evaluation and prospectus. In J.F. Noonan (Ed.), Learning about teaching. New Directions for Teaching and Learning, No. 4, San Francisco: Jossey-Bass.

Oberg, A. (1985, June). Developing self-reflective knowledge of professional practice through journal writing. Paper presented at the Annual Meeting of the Canadian Association for Curriculum Studies, Montreal, Quebec.

Sanders, D.P. \& McCutcheon, G. (April, 1984). On the evolution of teachers' theories of action through action research. Paper presented at the Annual Meeting of the American Education Research Association, New Orleans.

Schon, D. (1983). The reflective practitioner. New York: Basic Books.

Tripp, D. (1984). Action research and professional development. A discussion paper for the Australian College of Education Project, 1984-1985.

Wilson, R., Douglas, D., \& Harrington, D. (1984). Using consultation to improve teaching. Berkeley, CA: Teaching Innovation and Evaluation Services, University of California at Berkeley. (ERIC Document Reproduction Service No. ED 242271). 